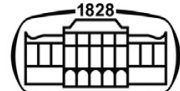

AKADÉMIAI KIADÓ

Journal of Behavioral Addictions

10 (2021) 1, 159-168

D01:

$10.1556 / 2006.2020 .00105$

(c) 2020 The Author(s)

\section{FULL-LENGTH REPORT}

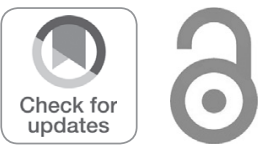

\section{Assessing ICD-11 gaming disorder in adolescent gamers by parental ratings: Development and validation of the Gaming Disorder Scale for Parents (GADIS-P)}

\author{
KERSTIN PASCHKE ${ }^{*}$ ๑, MARIA ISABELLA AUSTERMANN and \\ RAINER THOMASIUS
}

German Center for Addiction Research in Childhood and Adolescence (DZSKJ), University Medical Center Hamburg-Eppendorf (UKE), Martinistrasse 52, D-20246 Hamburg, Germany

Received: July 30,2020 • Revised manuscript received: October 4, 2020; November 5, 2020 - Accepted: December 6, 2020

Published online: January 7, 2021

\begin{abstract}
Background and aims: The addiction to digital games is associated with substantial impairments in daily functioning and adolescents are particularly at risk. Screening instruments for the new ICD-11 diagnosis Gaming Disorder (GD) are rare and only include self-ratings thus far. Since adolescents' insight might be limited due to young age or symptom denial, external ratings are essential. We therefore aimed to develop and validate the Gaming Disorder Scale for Parents (GADIS-P) in a representative sample of parents and young gamers. Methods: GADIS-P was developed as an adaptation of a recently published self-rating scale. It was validated in 800 parents and their frequently gaming children between 10 and 17 years with standardized questionnaires in an online survey. Item structure was investigated by confirmatory factorial analysis. Gaming time, pathological gaming according to DSM-5, emotional dysregulation, and academic performance were used to derive criterion validity. Accordance with selfratings was determined. ROC-Analyses were computed to determine cut-off values. Results: A presumed two-factorial structure of GADIS-P could be confirmed describing cognitive-behavioral symptoms and negative consequences. The instrument showed good to excellent internal consistency (Cronbach's $\alpha=$ $0.89-0.92$, McDonald's $\omega=0.92-0.95)$ and criterion validity with moderate to strong correlations regarding gaming behavior $(r / Q=0.35-0.76)$, excellent discriminatory power, and moderate accordance with the adolescents' self-ratings (kappa $=0.47-0.58$ ). Discussion and conclusions: As the first successfully validated tool for the assessment of ICD-11 GD in adolescents by parental judgment, GADIS-P can make an important contribution to reliable GD screening in clinical and research settings.
\end{abstract}

\section{KEYWORDS}

gaming disorder, ICD-11, adolescents, parents, screening

\section{INTRODUCTION}

The addiction to digital games is a severe phenomenon with substantial consequences in psychosocial life. Since their capabilities of cognitive control are still under development while neural reward functions are fully developed (Konrad, Firk, \& Uhlhaas, 2013), adolescents are particularly at risk to develop pathological gaming behavior (Yuan et al., 2016). According prevalence rates range between 1.2 and 5.9\% in Europe, Asia, and Australia (Sugaya, Shirasaka, Takahashi, \& Kanda, 2019).

Referring to online statistics, game applications are the most popular among smartphone apps and the revenue in the online games segment has increased during the last years and especially months (statista, 2020a, 2020b). A recent online survey by GlobalWebIndex on the effects of the COVID-19 pandemic investigating 17,143 adolescent and adult internet users 
revealed a worldwide increase of smartphone usage and digital media consumption, including games, especially in young users since mid-March (GWI, 2020).

Most recent assessment tools are based on the diagnostic criteria for the Internet Gaming Disorder (IGD) - a "condition warranting more clinical research and experience" in the Diagnostic and Statistical Manual of Mental Disorders 5 (DSM-5) in 2013 (American Psychiatric Association, 2013). The IGD comprises nine criteria referring to (internet) gaming on any electronic device: (1) preoccupation with gaming, (2) withdrawal when not playing, (3) tolerance, (4) unsuccessful attempts to reduce or stop gaming, (5) giving up other activities, (6) continuation of gaming despite problems, (7) deceiving or covering up gaming, (8) gaming to escape adverse moods, and (9) risking or losing relationships or career opportunities due of excessive gaming. The diagnosis Gaming Disorder (GD) has been recently included in the 11th revision of the International Classification of Diseases (ICD-11). Accordingly, the following criteria concerning the on-/off-line gaming behavior must be continuously or episodically present, and normally evident over a period of at least 12 months (World Health Organization, 2018): (1) impaired control over gaming, (2) increasing priority given to gaming over other activities and (3) continuation or escalation of gaming despite the occurrence of negative consequences. This behavior leads to clinically significant distress or impairment of personal (mental and/or physical well-being), social, educational, work-related, and financial functions (King et al., 2020; Reed et al., 2019). Thus, in contrast to DSM-5, symptoms and disability aspects both need to be present for the diagnosis to be fulfilled. Moreover, the term hazardous gaming (HG) has been introduced by the ICD-11 suggesting a persistent gaming pattern in awareness of an increased risk for physical or psychological harm to self or others due to the frequency and duration of gaming, neglect of alternative activities, risky gaming-associated behaviors, and/or negative gaming consequences.

As the first ICD-11 GD screening tool for adolescents, the Gaming Disorder Scale for Adolescents (GADIS-A) was recently published by the authors (Paschke, Austermann, \& Thomasius, 2020). It was introduced as a two-factorial questionnaire with good to excellent internal consistency, validity, and discriminatory power. The items reflect the factors cognitive-behavioral GD symptoms and negative consequences as well as a time criterion.

In clinical practice, questionnaires are regularly used for screening and diagnostic purposes including self-reports but also external ratings, usually by parents (Döpfner \& Petermann, 2012). Parental ratings can add important information since introspection of children and adolescents might be limited due to young age, learning difficulties, or symptom denial - especially for behavioral problems (Aebi et al., 2017). Moreover, parents are usually the ones who are first aware of problematic behavior of their children and seek professional help. If the children refuse clinical attendance, a parental rating might be the only available resource for an initial evaluation. In the case of parents potentially overestimating problems related to the use of games, parental screeners might help creating reassurance by a more objective view. Currently available questionnaires to assess DSM-5 IGD by parents include the Gaming Addiction Identification Test for Parents (GAIT-P, Vadlin, Åslund, Rehn, \& Nilsson, 2015) and the Parental Internet Gaming Disorder Scale (PIGDS, Wartberg, Zieglmeier, \& Kammerl, 2017).

Since the ICD-11 will come into effect in January 2022, an instrument to assess GD in young gamers by parental ratings is urgently needed. To the best of our knowledge, despite clinical and research needs, no validated GD screening instrument for children and adolescents using parental ratings is available at this point. Therefore, the aims of this study were (1) the development of an parentally rated GD screening instrument for adolescents (Gaming Disorder Scale for Parents, GADIS-P) by adapting GADIS-A, (2) the investigation of the psychometric properties of the newly developed scale, (3) its validation in a representative sample of parents and their 10- to 17-year-old frequent gamers, and (4) the determination of the accordance between parental and adolescent ratings.

\section{METHODS}

\section{Participants and procedure}

One thousand two hundred twenty-one parents successfully paired with one respective child between 10 and 17 years of the same household participated in this study. Of these, only dyads were included where the parents reported gaming of their children at least once a week. Representativity of the initial sample was ensured regarding proportions of sex and age as well as region of residence using a random sampling method by the well-established German market research and opinion polling company forsa that collected the data as part of a large online survey (for details see Paschke et al., 2020, Supplementary Methods, and Fig. S1).

\section{Measures}

Gaming Disorder (GD). Adolescents' GD symptoms based on the ICD-11 criteria were externally assessed by the newly developed Gaming Disorder Scale for Parents (GADIS-P). The nine symptom items plus one timing question were adapted from GADIS-A (Paschke et al., 2020) to fit parental instead of self-report rating. The content and the Likert-scale response format to indicate how strongly they agree with the given statements thinking of the last 12 months were maintained (see Supplementary Methods). Table 1 shows the English GADIS-P version with the corresponding ICD11 and DSM-5 criteria (for the original German version refer to Table S1). According to the GADIS-A evaluation, the responses to items $1,2,4$, and 5 summed up to a maximum score of 16 to depict the cognitive-behavioral symptoms of GD. The responses to items $3,6,7,8$, and 9 summed up to a maximum score of 20 for the negative consequences of GD. Higher scores indicated more problems. To address the 
Table 1. Two-factorial GADIS-P items with corresponding ICD-11 and DSM-5 criteria

\begin{tabular}{l}
\hline ICD-11 criteria \\
\hline (Corresponding DSM-5 Item) \\
\hline A Impaired control over \\
gaming (e.g., onset, \\
frequency, intensity, \\
duration, termination, \\
context). \\
(Unsuccessful attempts to \\
reduce or stop gaming.) \\
\\
B Increasing priority given \\
to gaming to the extent \\
that gaming takes \\
precedence over other \\
life interests and daily \\
activities.
\end{tabular}

(Giving up other activities.)

\section{Continuation or escalation of gaming despite the occurrence of negative consequences.}

\section{(Continuation of gaming} despite problems.)

D The behavior pattern is of sufficient severity to result in significant impairment in personal, family, social, educational, occupational or other important areas of functioning.

\section{GADIS-P items}

Thinking of the last 12 months, how strongly do you agree with the following statements?

1 My child often plays games more frequently and longer than he/she planned to or agreed upon with me or my partner. ${ }^{a}$

2 My child often cannot stop gaming even though it would be sensible to do so or for example I have told him/her to stop. ${ }^{\mathrm{a}}$

3 My child often does not pursue interests outside the digital world (e.g., meeting friends or partner in real life, attending sports clubs/ societies, reading books, making music) because he/she prefers gaming. ${ }^{\mathrm{a}}$

4 My child neglects daily duties (e.g., grocery shopping, cleaning, tidying up after himself/ herself, tidying his/her room, obligations for school/apprenticeship/ job) because he/she prefers gaming. ${ }^{\text {a }}$

5 My child usually continues gaming even though it causes him/her stress with others (e.g., with me or my partner, siblings, friends, partner, teachers). ${ }^{\mathrm{a}}$

6 My child continues gaming although it harms his/her performance at school/ apprenticeship/job (e.g., by being late, not participating in class, neglecting homework, worse grades). ${ }^{\mathrm{a}}$

7 Due to gaming, my child neglects his/her appearance, personal hygiene, and/or health (e.g., sleep, nutrition, exercise). ${ }^{a}$

8 Due to gaming, my child risks losing important contacts (friends, family, partner) or have lost them already. ${ }^{a}$

(continued)
Table 1. Continued

\begin{tabular}{|c|c|c|c|}
\hline \multicolumn{2}{|c|}{ ICD-11 criteria } & \multicolumn{2}{|r|}{ GADIS-P items } \\
\hline & Corresponding DSM-5 Item) & & $\begin{array}{l}\text { nking of the last } 12 \text { months, } \\
\text { strongly do you agree with } \\
\text { he following statements? }\end{array}$ \\
\hline & $\begin{array}{l}\text { Risking or losing } \\
\text { relationships or career } \\
\text { opportunities due to } \\
\text { excessive gaming.) }\end{array}$ & 9 & $\begin{array}{l}\text { Due to gaming, my child has } \\
\text { disadvantages at school/ } \\
\text { apprenticeship/job (e.g., } \\
\text { bad [final] grades, } \\
\text { inability to continue to the } \\
\text { next grade/no graduation, } \\
\text { no apprenticeship or } \\
\text { university spot, poor } \\
\text { reference, warning/ } \\
\text { dismissal). }\end{array}$ \\
\hline $\mathbf{E}$ & $\begin{array}{l}\text { The pattern of gaming } \\
\text { behavior may be } \\
\text { continuous or episodic } \\
\text { and recurrent and } \\
\text { normally evident over a } \\
\text { period of at least } 12 \\
\text { months. }\end{array}$ & 10 & $\begin{array}{l}\text { How often did your child } \\
\text { experience such } \\
\text { problems, conflicts, or } \\
\text { difficulties due to } \\
\text { gaming during the past } \\
\text { year? Did this only } \\
\text { occur on single days, } \\
\text { during longer periods of } \\
\text { several days to weeks, or } \\
\text { was it almost daily? }\end{array}$ \\
\hline
\end{tabular}

Notes:

${ }^{a}$ Response options: 5-point Likert-Scale: "strongly disagree” "strongly agree".

besponse options: "not at all", "only on single days", "during longer periods", "almost daily".

ICD-11-time criterion, the frequency of the mentioned problems, conflicts or difficulties due to gaming behavior within the last 12 months was queried. They needed to be present daily or at least for longer periods to consider the time criterion as fulfilled, indicated by a score of 2 or 3 .

To compare GD self- and parental ratings, the investigated adolescents completed the GADIS-A to indicate GD symptoms and consequences during the last 12 months. Subscale sum scores were calculated according to the description above. Cutoff values of 9 for the first and 5 for the second factor were applied (Paschke et al., 2020). Adolescents were classified as gaming disordered when both sum scores were greater than the cut-off values and the time criterion was fulfilled.

To assess Internet Gaming Disorder symptoms according to DSM-5 the Internet Gaming Disorder Scale (IGDS, Lemmens, Valkenburg, \& Gentile, 2015) was used in its parental judgment version (PIGDS, Wartberg et al., 2019). The PIGDS is a one-factor, polythetic scale with 9 items in a dichotomous response format (no/yes) with a higher total sum of the yes-responses indicating a higher risk for IGD. It showed a good accordance between parental and self-ratings as well as good psychometric properties (Wartberg et al., 2019). PIGDS items 4, 6, 8, and 9 correspond to ICD-11 criteria and were therefore used for GD estimation (Jo et al., 2019; Ko, Lin, Lin, \& Yen, 2019). Adolescents were classified with GD when all four items were answered with yes. 
Adolescent gaming time, emotional dysregulation, and academic functioning. Parents and the corresponding adolescents rated the average frequency of gaming per week (in days), per school day, and per weekend day (in hours). Out of the latter two, a mean gaming time was computed (in hours).

Adolescent problems in emotional regulation were assessed by the self-rating 18-item short form of the Difficulties in Emotional Regulation Scale, with a higher sum score indicating more problems in emotional regulation (DERS-SF, Kaufman et al., 2016).

Moreover, adolescents reported days of absence from school/work during the previous three months, their past-term final grades in the subjects German, Mathematics, and first foreign language and their grade development as a measure of academic performance (see Supplementary Methods).

\section{Statistical analysis}

A detailed methods description can be found in the Supplements.

Parent-child dyads with severe missing values in the data of the adolescents, parents, or both, were excluded from further analyses. Missing values were classified as severe when no responses were available for more than one third of the items of GADIS-P and PIGDS (parents), GADIS-A and DERS (adolescents) as well as no response to the GADIS-P and GADIS-A timing item.

Factor structure was examined by a confirmatory factor analysis (CFA) with robust minimal residuals (OLS). To proof the structure of GADIS-P to be comparable to GADIS-A, the CFA model was built analogous to the GADIS-A CFA model with items 3, 6, 7, 8, and 9 reflecting factor 1 and items 1, 2, 4, and 5 reflecting factor 2 (Paschke et al., 2020). Model goodness of fit was assumed according to the following criteria: $\chi 2 / \mathrm{df}$ ratio $<5$, root mean square error of approximation (RMSEA) $<0.08$, standardized root mean squared residual $(\mathrm{SRMR})<0.08$, Tucker-Lewis Index (TLI) $\geq 0.95$, comparative fit index (CFI) $\geq 0.95$ (Hooper, Coughlan, \& Mullen, 2008).

Internal consistency was calculated by Cronbach's $\alpha$ and McDonald's $\omega$. Criterion validity was obtained by correlating the GADIS-P sum score with the GADIS-A and PIGDS-sum score, the gaming days per week, as well as the mean gaming hours per day (both reported by the adolescents), DERS-SFsum score, days of absence (during the last three months), grades-sum score, and grade development (during the last school term) applying Pearson or Spearman rank correlation tests according to the item/scale distribution.

A receiver operating characteristic (ROC) curve analysis was conducted to compare sensitivity and specificity across GADIS-P scores to predict GD according to ICD-11 related PIGDS items. Cut-off points were determined based on Youden's criterion. Goodness of differentiation between the two diagnostic groups was computed by the area under curve value (AUV). The received cut-off point was then applied to classify adolescents with GD if the ICD-11-time criterion was fulfilled. Groups were compared regarding age, sex, GADIS-P and -A score, PIGDS score, gaming days per week, mean gaming hours per day, absence, grade-sum score, and grades development by a MANOVA with posthoc $\chi^{2}$ and Scheffé tests. The accordance rate was determined by comparing the GD classification based on GADIS$\mathrm{P}$ with the one based on GADIS-A using Cohen's kappa (unweighted).

\section{Ethics}

The study was conducted in accordance with the relevant national and institutional committees on human experimentation, complied with the Declaration of Helsinki, and was approved by the Local Psychological Ethics Commission at the Center for Psychosocial Medicine (LPEK) of the University Medical Center Hamburg-Eppendorf (UKE). Each participant gave his/her informed consent prior to enrollment.

\section{RESULTS}

One thousand thirty-seven out of one thousand two hundred twenty-one parents (496 [47.8\%] fathers and 541 [52.2\%] mothers) with a mean age of 46.38 years (standard deviation 2.37; range 28-75) reported a regular use of digital games (at least once a week) of his/her child.

Two hundred thirty-seven parent-child dyads had to be excluded from further analyses due to severe missing values. Table 2 shows the sample characteristics of the resulting sample $(N=800)$. The sociodemographic sample characteristics of the excluded dyads and the resulting sample could be regarded comparable (Table S3).

For the sample characteristics of the initial sample (including non-(regular) gaming adolescents) refer to Table S2.

Mothers scored higher on GADIS-P factor 1 than fathers $(t(760.57)=2.66, P=0.008)$ but did not differ in scoring on factor $2(t(775.2)=0.69, P=0.49)$ and the timing item $\left(\chi^{2}(3)=1.82, P=0.61\right)$.

\section{Factor structure}

A two-factor model for the GADIS-P was tested with confirmatory factor analysis. The fit indices yielded mixed results: The CFI of 0.995 , the TLI of 0.993 were excellent, the SRMR of 0.056 was acceptable, while the $\chi^{2} / \mathrm{df}$ ratio $\left(\chi^{2}(26)\right.$ $=215.72, P<0.001$, ratio $=8.3$ ) and the RMSEA value of 0.096 indicated poor fit. Yet, the two factor model fitted the data significantly better than a single-factor solution $\left(\chi^{2}(1)\right.$ $=470.73, P<0.001)$. All items showed significant positive factor loadings, with standardized coefficients ranging from 0.83 to 0.90 . As in GADIS-A, GADIS-P items 7 to 9 (personal, social, and academic/occupational impairments), 6 (continuation despite academic/occupational disadvantages), and 3 (loss of other interests due to gaming) loaded significantly on factor 1 , thus, reflecting impending or manifest consequences due to gaming. Identical to GADISA, GADIS-P items 1 and 2 (loss of control), 5 (continuation despite social stress) and 4 (neglecting daily duties) loaded 
Table 2. Sociodemographic characteristics of final sample ${ }^{\mathrm{a}}$

\begin{tabular}{|c|c|c|}
\hline $\begin{array}{l}\text { Variables/ } \\
\text { Categories }\end{array}$ & $\begin{array}{c}\text { Parents } \\
\mathrm{N}(\%) / \text { mean }(\mathrm{SD} ; \\
\text { range })\end{array}$ & $\begin{array}{c}\text { Adolescents } \\
\mathrm{N}(\%) / \text { mean }(\mathrm{SD} ; \\
\text { range) }\end{array}$ \\
\hline Absolute frequency & 800 & 800 \\
\hline \multicolumn{3}{|l|}{ Gender } \\
\hline Male & $496(47.8)$ & $469(58.6)$ \\
\hline Female & $541(52.2)$ & $331(41.4)$ \\
\hline Age in years & $46.38(7.93 ; 28-75)$ & $12.99(2.37 ; 10-17)$ \\
\hline \multicolumn{3}{|l|}{ Relationship status } \\
\hline biological child & & $695(86.9)$ \\
\hline adoptive child & & $8(1.0)$ \\
\hline Stepchild & & $59(7.4)$ \\
\hline other ${ }^{b}$ & & $38(4.8)$ \\
\hline \multicolumn{3}{|l|}{ Partnership ${ }^{\mathrm{c}}$} \\
\hline Yes & $747(93.7)$ & \\
\hline $\begin{array}{l}\text { in common } \\
\text { household }\end{array}$ & $693(87.0)$ & \\
\hline with child's parent & $622(83.7)$ & \\
\hline \multicolumn{3}{|l|}{ Education level $^{\mathrm{d}, \mathrm{e}}$} \\
\hline High & $282(27.2)$ & $433(55.9)$ \\
\hline Medium & $625(60.3)$ & $279(36.0)$ \\
\hline Low & $95(9.2)$ & $63(7.1)$ \\
\hline \multicolumn{3}{|l|}{ Occupation } \\
\hline $\begin{array}{l}\text { full-time } \\
\text { employment }^{\mathrm{f}} / \\
\text { school attendance }^{\mathrm{g}}\end{array}$ & $615(59.4)$ & $749(93.7)$ \\
\hline $\begin{array}{l}\text { part-time } \\
\text { employment }^{\mathrm{f}} / \\
\text { apprenticeship }^{\mathrm{g}}\end{array}$ & $303(29.3)$ & $40(5.0)$ \\
\hline other ${ }^{\mathrm{h}, \mathrm{i}}$ & $118(11.4)$ & $10(1.3)$ \\
\hline
\end{tabular}

Notes: $\mathrm{N}=$ absolute frequency; $\mathrm{SD}=$ standard deviation.

a dyads with frequently gaming adolescents, i.e. adolescents use digital games at least once a week.

${ }^{\mathrm{b}}$ foster child/not specified; ${ }^{\mathrm{c}}$ no response $n=3$; $^{\mathrm{d}}$ for parents: highest level achieved - high $=$ bachelor/master's degree to doctorate $(\mathrm{PhD})$, medium = secondary school-leaving certificate (Realschulabschluss)/university entry qualification (Abitur)/ completed apprenticeship, low $=$ no or lower school-leaving certificate (Hauptschulabschluss); ${ }^{\mathrm{e}}$ for adolescents: (prospective) school leaving certificate (based on the current school performance) - high $=$ university entry qualification (Abitur), medium $=$ secondary school certificate (Realschulabschluss); low $=$ no/ special-school (Förderschulabschluss)/lower school certificate (Hauptschulabschluss); ${ }^{\mathrm{f}}$ parental sample; ${ }^{\mathrm{g}}$ adolescent sample; ${ }^{\mathrm{h}}$ for parents: job-seeking, welfare recipient, pensioners, disabled, trainee, student, no specification; ${ }^{i}$ for adolescents: university students, in voluntary service, military service, other occupation, or unemployed.

significantly on factor 2 mirroring cognitive-behavioral gaming symptoms (Fig. 1). The two latent factors correlated significant positive $(r=0.65, P>0.001)$, supporting the view that adolescents with a higher load of cognitive-behavioral symptoms are more likely to report negative consequences of the gaming behavior. The proportion of explained variance by the scale items was 0.76 for factor 1 and 0.78 for factor 2. Tables S4 and S5 present inter-item correlations and the relative item-response frequencies. All items showed a moderate correlation with the additional timing item $(0.45$ $\leq r \leq 0.67)$.

\section{Internal consistency}

For the total GADIS-P scale Cronbach's $\alpha$ of 0.92 and McDonald's $\omega$ of 0.95 were computed. For each subscale reflecting the two factors, Cronbach's $\alpha$ revealed a value 0.89 and McDonald's $\omega$ of 0.92 . Thus, the total GADIS-P and reflects excellent and each second subscale good internal consistency.

\section{Criterion validity}

Analyses revealed strong positive correlations between the GADIS-P sum score and the amount of fulfilled DSM-5 criteria of problematic gaming (gathered by PIGDS sum score, $r=0.74, P<0.001)$ indicating excellent criterion validity. GADIS-P sum score and gaming days per week (Spearman's $>=0.35, P<0.001$ ) as well as the mean gaming hours per day reported by the adolescents $(r=0.41$, $P<0.001)$ correlated positively in a moderate manner. An overall good criterion validity is mirrored by these results. Weak positive correlations could be found between the GADIS-P- and the DERS-sum score as a measure of emotional dysregulation $(r=0.39, P<0.001)$ and with the sum of the grades of the three major subjects at school $(r=$ $0.16)$. The improvement of grades correlated significantly negative with the GADIS-P score in a weak manner $(r=$ $-0.14, P<0.001)$. Significant but negligible positive correlations were computed for the GADIS-P total score with the days of absence from school or work (Spearman's $>=0.15$, $P<0.001$ ). For visualization please refer to Fig. 1 (right column).

\section{Sensitivity and specificity}

Adolescents were classified as gaming disordered based on the ICD-11 items of the PIGDS. This classification was included into two ROC curve analyses together with the two GADIS-P subscale sum scores according to the two-factorial scale structure. Following Youden's criterion, the optimal cut-off for factor 1 was 5.5 (95\% CI 2.5-6.5) with a specificity of $84.13 \%$ (95\% CI $66.48-90.57)$, a sensitivity of $86.96 \%$ (95\% CI 76.81-98.55), and an AUC value of $92.2 \%$ (95\% CI 89.7-94.7). For factor 2 a cut-off value of $9.5(95 \%$ CI 7.5-9.5) with a specificity of $86.05 \%$ (95\% CI $74.42-$ 88.78 ), a sensitivity of $92.75 \%$ (95\% CI $85.51-100.00$ ), and an AUC value of $93.7 \%$ (95\% CI 91.8-95.6) was computed. Both AUC values indicate excellent differentiation.

Applying the cut-off of $>5$ for factor 1 and $>9$ for factor 2 as well as considering the ICD-11-time item (symptoms at least for longer periods or daily), $4.8 \%$ (95\% CI 3.3-6.2) of the adolescent gamers were classified as gaming disordered (GD, $N=38$ ). Strong effects were revealed with (per definition) higher GADIS-P, but also higher GADIS-A, PIGDS-, and DERS-sum scores as well as a longer gaming duration per day in GD adolescents compared to Non-GD gamers. Except for age, all dependent variables (sex, GADIS-P 


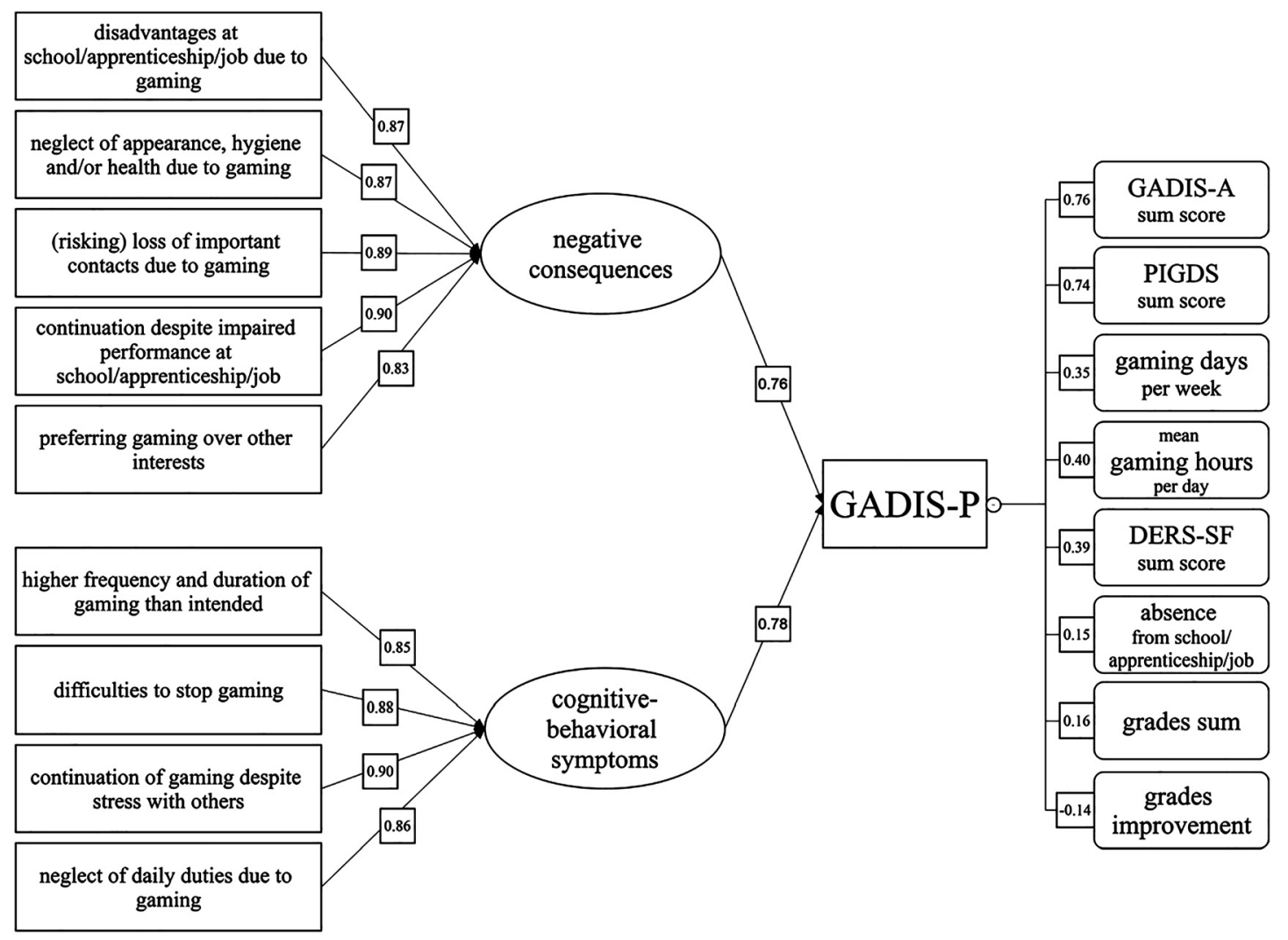

Fig. 1. Standardized factor loadings on two GADIS-P factors and correlations with criteria. Standardized factor loadings on GADIS-P factor 1 (negative consequences) and GADIS-P factor 2 (cognitive-behavioral gaming symptoms) are depicted on the left side together with the proportion of explained variance. Correlation coefficients with criteria are presented on the right side. All standardized factor loadings and correlations were significant with $\mathrm{p}$ values $<0.001$. The absence from school/apprenticeship/job refers to the prior three months, grades sum (sum of grades in mathematics, German, first foreign language on a scale from 1 to 6 with higher scores indicating worse performance), and grades improvement to the previous term.

Abbreviations: GADIS-P = Gaming Disorder Scale for Parents; GADIS-A = Gaming Disorder Scale for Adolescents; PIGDS = Parental Internet Gaming Disorder Scale; DERS = Difficulties in Emotion Regulation Scale

subscale sum scores, parental rating of frequency of GD symptoms, GADIS-A subscale sum score, PIGDS sum score, days of gaming per week, mean gaming hours per day, DERS sum, absence, grades sum score and grades development) reached significance when being included in a MANOVA with the cut-off based classified gaming disorder (Pillai score $(1,654)=0.38, \mathrm{~F}(14,641)=28.48, P<0.001$; Table S4). Moderate effects could be shown for sex with significant more boys than girls in the GD group, a higher gaming frequency per week, more days of absence from school or work, and less academic grade improvement during the last term in the affected gamer group. The sum of grades in the three major school subjects was worse in the GD compared to the unaffected group with a small effect size. Moreover, on a descriptive level the GD affected adolescents were about 8 months older (13.66 vs. 12.96 years) although no significance was reached. For details on the MANOVA refer to Table 3.

\section{Accordance rate}

Strong positive correlations existed between the total $(r=$ $0.76, P<0.001)$, factor $1(r=0.74, P<0.001)$, and factor 2 scores $(r=0.71, P<0.001)$ of GADIS-P and GADIS-A and a moderate correlation for the timing item $(r=0.61, P<$ $0.001)$.

The classification of adolescents regarding GD based on GADIS-P and GADIS-A is associated with a kappa coefficient of 0.46 . When looking on the factorial level, a kappa coefficient of 0.58 was computed for factor 1 and of 0.52 for factor 2. For the time criterion, a kappa coefficient of 0.47 was calculated. Thus, all coefficients indicate a moderate concordance between the parental and the adolescent rating. Table 4 shows the frequencies and accordance of GD positively and negatively screened adolescents by the parental and the adolescent judgment.

\section{DISCUSSION}

To the best of our knowledge, this study is the first to introduce a new ICD-11-based screening tool to support diagnosis of disordered gaming in children and adolescents by parental ratings. GADIS-P could be successfully validated in a representative sample of parents and their frequently 
Table 3. Frequencies and results of post-hoc MANOVA tests of GD/Non-GD adolescents (according to GADIS-P)

\begin{tabular}{|c|c|c|c|c|c|c|c|}
\hline Variables & No GD & GD & $\begin{array}{c}\mathrm{F} \\
\text { value }\end{array}$ & $\begin{array}{c}P \text { value } \\
(\text { MANOVA) }\end{array}$ & $\begin{array}{c}\chi^{2} / \\
\text { Scheffé }\end{array}$ & $\begin{array}{l}P \text { value (post- } \\
\text { hoc test) }\end{array}$ & $\begin{array}{l}\text { Cramer's V/ } \\
\text { Cohen's d }\end{array}$ \\
\hline Absolute frequency & 762 & 38 & & & & & \\
\hline Relative frequency $[95 \% \mathrm{CI}]$ & $\begin{array}{c}95.25[93.78- \\
96.72]\end{array}$ & $\begin{array}{l}4.75[3.28- \\
\quad 6.22]\end{array}$ & & & & & \\
\hline Mean age (SE) & $12.96(0.09)$ & $13.66(0.32)$ & & & 0.7 & 0.075 & - \\
\hline Female sex $[95 \% \mathrm{CI}]$ & $\begin{array}{c}42.65[39.14- \\
46.16]\end{array}$ & $\begin{array}{l}15.79[4.2- \\
27.38]\end{array}$ & 3.1 & 0.079 & -9.69 & 0.002 & 0.12 \\
\hline $\begin{array}{l}\text { Mean GADIS-P factor } 1 \\
\text { score (SE) }\end{array}$ & $2.52(0.12)$ & $11.95(0.69)$ & 7.3 & 0.007 & 9.43 & $<0.001$ & 2.8 \\
\hline $\begin{array}{l}\text { Mean GADIS-P factor } 2 \\
\text { score (SE) }\end{array}$ & $5.35(0.14)$ & $13.47(0.32)$ & 224.48 & $<0.001$ & 8.12 & $<0.001$ & 2.11 \\
\hline Mean timing score (SE) & $0.73(0.02)$ & $2.37(0.08)$ & 139.52 & $<0.001$ & 1.64 & $<0.001$ & 3.04 \\
\hline $\begin{array}{l}\text { Mean GADIS-A factor } 1 \\
\text { score (SE) }\end{array}$ & $2.06(0.11)$ & $10.34(0.86)$ & 281.36 & $<0.001$ & 8.28 & $<0.001$ & 2.53 \\
\hline $\begin{array}{l}\text { Mean GADIS-A factor } 2 \\
\text { score (SE) }\end{array}$ & $4.74(0.14)$ & $12.37(0.48)$ & 164.96 & $<0.001$ & 7.63 & $<0.001$ & 2.02 \\
\hline Mean PIGDS sum score (SE) & $2.41(0.09)$ & $7.68(0.27)$ & 117.12 & $<0.001$ & 5.27 & $<0.001$ & 2.19 \\
\hline $\begin{array}{l}\text { Mean gaming days per week } \\
\text { (SE) }\end{array}$ & $4.89(0.08)$ & $6.63(0.17)$ & 146.95 & $<0.001$ & 1.74 & $<0.001$ & 0.76 \\
\hline $\begin{array}{l}\text { Mean gaming hours per day } \\
(\mathrm{SE})^{\mathrm{a}}\end{array}$ & $111.89(16.9)$ & $\begin{array}{r}245.67 \\
(25.7)\end{array}$ & 22.96 & $<0.001$ & 133.78 & $<0.001$ & 1.25 \\
\hline Mean DERS sum score (SE) & $39.96(0.44)$ & $52.87(1.92)$ & 31.24 & $<0.001$ & 12.9 & $<0.001$ & 1.07 \\
\hline $\begin{array}{l}\text { Mean days of absence from } \\
\text { school/work }(\mathrm{SE})^{\mathrm{b}}\end{array}$ & $1.91(0.14)$ & $4.67(1.35)$ & 26.68 & $<0.001$ & 2.76 & $<0.001$ & 0.65 \\
\hline Mean sum of grades $(\mathrm{SE})^{\mathrm{c}, \mathrm{d}}$ & $6.3(0.09)$ & $7.21(0.52)$ & 5.07 & 0.025 & 0.9 & 0.034 & 0.37 \\
\hline $\begin{array}{l}\text { Mean grades improvement } \\
(\mathrm{SE})^{\mathrm{d}}\end{array}$ & $3.21(0.02)$ & $2.85(0.12)$ & 5.42 & 0.02 & -0.35 & 0.002 & 0.54 \\
\hline
\end{tabular}

Notes: MANOVA = Multivariate Analysis of Variance, $\mathrm{SE}=$ standard error of the mean, $\mathrm{CI}=$ Confidence Interval, GD $=$ Gaming Disorder, GADIS-P = Gaming Disorder Scale for Parents, GADIS-A = Gaming Disorder Scale for Adolescents, factor $1=$ negative consequences, factor 2 = cognitive-behavioral symptoms; PIGDS = Parental Internet Gaming Disorder Scale, DERS = Difficulties in Emotion Regulation Scale. p-values $<0.05$ are considered significant and are shown in bold.

${ }^{\mathrm{a}}$ Mean of gaming hours per school day and gaming hours per weekend day.

${ }^{\mathrm{b}}$ Within last three months.

${ }^{\mathrm{c}}$ Sum of grades in mathematics, German, and first foreign language (each ranging 1-6, with higher scores indicating worse performance).

${ }^{\mathrm{d}}$ During previous school term.

gaming children as a tool with good to excellent internal consistency and criterion validity, excellent discriminatory power, as well as moderate accordance rates with adolescents' self-ratings. The questionnaire comprises nine GDsymptom items and one item reflecting symptom frequency according to the ICD-11-time criterion. Thus, besides being psychometrically robust, it is highly economic and feasible.

GADIS-P was adapted from the adolescent self-rating tool GADIS-A. The two-factorial structure of GADIS-A could be approved in GADIS-P by a confirmatory factorial analysis. The two factors are best described as mirroring

Table 4. Absolute frequencies and accordance of GD positively and negatively screened adolescents

\begin{tabular}{lccc}
\hline & GADIS-P + & GADIS-P - & Accordance (\%) \\
\hline GADIS-A + & 16 & 10 & 61.54 \\
GADIS-A - & 26 & 748 & 96.64 \\
Accordance (\%) & 38.1 & 98.68 & 95.5 \\
\hline
\end{tabular}

Notes: + positively screened, - negatively screened. cognitive-behavioral symptoms, such as increased gaming frequency and duration, the inability to stop gaming, or the neglect of daily duties, and negative consequences due to the gaming pattern, such as the loss of important contacts, withdrawal, poor health, or lower educational achievements. The confirmed two-factorial solution is contradictory to approaches where symptoms and impairments are not weighted equally. This is the case in DSM-5 based questionnaires like the IGDS-SF (Lemmens et al., 2015) or the four-item scale GDT addressing the three ICD-11 symptom criteria and the impairment criterion by one item each (Pontes et al., 2019). Notably, considering the gaming pattern and the resulting negative consequences leading to significant impairments to equal weights is in line with the biaxial model of addiction and the ICD-11 innovations (Reed et al., 2019; Wakefield, 2015). Accordingly, besides specific symptoms, adverse outcomes must be present in order to define the gaming pattern as disordered. Without the fulfillment of the latter, but in significant presence of the cognitive-behavioral symptoms, a hazardous gaming pattern can be assumed (World Health Organization, 2018). 
As in the self-rating scale, the time criterion was included to reduce potential overestimation by recall biases (Coughlin, 1990) or exaggeration (Jeong et al., 2018). The cut-off values of the two subscales revealed by the ROC curve analysis were identical with those of the GADIS-A, indicating a good comparability of the self- and external rating instrument. This was supported by strong correlations between both scales and a moderate concordance value. According to the parental rating $4.8 \%$ (95\% CI 3.3-6.2) of the frequent gamers were classified as gaming disordered. This prevalence is comparable to the self-rating finding of $3.7 \%$ (95\% CI 2.4-5.0, Paschke et al., 2020). Disordered gamers could be clearly discriminated from the rest of the frequent gamers by their higher number of fulfilled DSM-5 criteria assessed by PIGDS, as well as the longer duration and higher frequency of gaming. Gaming time is often reported when characterizing disordered gamers (Darvesh et al., 2020). Higher DERS values indicating more problems in emotional regulation were found in disordered compared to nondisordered gamers. This is in line with the results of a large Hungarian survey reporting a higher proportion of dysfunctional emotion regulation strategies in problematic adolescent gamers (Kökönyei et al., 2019). Emotion regulation was identified as a general indicator of mental health problems including substance and behavioral addictions (Aldao, Nolen-Hoeksema, \& Schweizer, 2010; Estévez, Jáuregui, Sánchez-Marcos, López-González, \& Griffiths, 2017). Congruent with current scientific knowledge, the GD group contained a higher proportion of boys. This sex effect has been repeatedly shown in various studies (Sugaya et al., 2019). School problems are common in disordered gamers as a risk factor but also as a negative consequence (Kindt, Szász-Janocha, Rehbein, \& Lindenberg, 2019). Thus, the discrimination value of GADIS-P is supported by our finding of a higher proportion of school absence, less grade improvement and worse grades in general.

According to the presented results, GADIS-P has the potential to make an important contribution to the assessment of GD in the especially vulnerable target group of adolescents by parental ratings. Together with the adolescents' self-ratings, it supports standardized approaches for diagnostic screening in epidemiological, clinical, and neuroscientific research fields. Moreover, it allows a first evaluation of potentially problematic or even pathological gaming behavior when the adolescents themselves cannot provide (valid) information. This might be due to reduced introspection capabilities on the basis of a young age, learning disabilities, and/or symptom denial. The latter is of special interest since an association between disordered gaming and a tendency to use denial as a coping strategy has been reported, challenging the "practitioners in obtaining reliable assessment by self-report” (Schneider, King, \& Delfabbro, 2018, p. 905). When comparing the results of clinical interviews and questionnaires based on self-reports, Jeong and colleagues found a false negative rate of disordered gaming of $44 \%$ in adolescents (Jeong et al., 2018). The results of Hawi and colleagues suggest that even younger children than the ones investigated in our study already show addiction symptoms related to digital devices/applications (Hawi, Samaha, \& Griffiths, 2019). For these a selfreport instrument may not be appropriate in the majority of cases.

A clinical validation of the GADIS-P in future studies is desirable to warrant a broad usage in clinical settings. Even though a combination of self- and external ratings could be shown to be of high diagnostic value (Aebi et al., 2017), questionnaires should never be solely relied on for GD diagnosis. In addition to clinical expertise, the GADIS-P might rather serve as an economic screening tool that is easy to administer, e.g., before appointments. Moreover, the external rating might support a first evaluation of potentially disordered gaming when the target adolescent is not able to cooperate. Thus, GADIS-P may significantly extend currently available screening instruments to support an early GD diagnosis for adolescents. This is the prerequisite for initializing appropriate treatment and interventions with the aim of reducing symptoms and preventing severe secondary impairments, comorbidities, or even chronification.

\section{Limitations}

First, although online questionnaires are highly appreciated tools in large epidemiologic surveys for economic reasons, households without Internet access (about 5\% in Germany, statista, 2020c) could not be considered for this study. Moreover, missing data is a common problem in online surveys. The exclusion of parent-child dyads might have reduced representativeness but is a common cost of online instruments (especially when investigating parent-child dyads including young adolescents). It cannot be excluded that responses were influenced by other people, although the participants were instructed to respond on their own. Highest validity would have been obtained by face-to-face interviews, which are hard to realize in such large samples. The most severe limitation of this work is the not yet available external verification of the screening results by an experienced clinician. This would be the gold standard for concurrent validity. However, given the early stage of GD research and no yet available clinically validated screening alternatives, our study supports important steps towards an early detection of affected young gamers. Future studies should investigate the effects of sociodemographic variables on accordance rates, such as the sex of parents and adolescents or the educational background, by oversampling problematic gamers.

\section{CONCLUSIONS}

GADIS-P is the first available screening instrument for the assessment of GD in adolescents according to ICD-11 on the basis of parental ratings. It shows good to excellent internal consistency reliability and criterion validity as well as moderate accordance with adolescent self-ratings. Differentiation between pathological and non-pathological gamers was excellent. Moreover, a two-factorial structure supporting the ICD-11 approach could be confirmed. This includes the 
concern of gaming-related cognitive-behavioral symptoms and their negative consequences to equal weights. Furthermore, by including a temporal item, occasional gaming behavior-associated problems could be distinguished from outlasting ones - a necessary GD criterion. Thus, GADIS-P could be identified as a valid and reliable screening instrument for assessing disordered gaming easy to administer in busy clinical settings or for scientific surveys. It can complement clinical evaluations on the basis of self-ratings or enable an initial evaluation when self-rating is not available.

Funding sources: The current study is part of a parent-child survey that was financially supported by the German health insurance company DAK Gesundheit.

Authors' Contribution: KP and RT conceptualized and designed the study and decided to publish the paper. KP performed the statistical analysis. All authors interpreted the data. KP drafted the manuscript. MA prepared tables and figures, and formatting. All authors critically revised the draft for important intellectual content. All authors agreed to be accountable for all aspects of the work in ensuring that questions related to the accuracy or integrity of any part of the work are appropriately investigated and resolved. All authors gave final approval for the article to be published.

Conflict of interest: DAK Gesundheit had no role in the design of the study, collection, analyses, or interpretation of data, in the writing of the manuscript, or in the decision to publish the results. The authors declare no conflict of interest.

Acknowledgments: We thank Milan Röhricht for his language editing support.

\section{SUPPLEMENTARY DATA}

Supplementary data to this article can be found online at https://doi.org/10.1556/2006.2020.00105.

\section{REFERENCES}

Aebi, M., Kuhn, C., Banaschewski, T., Grimmer, Y., Poustka, L., Steinhausen, H.-C., et al. (2017). The contribution of parent and youth information to identify mental health disorders or problems in adolescents. Child and Adolescent Psychiatry and Mental Health, 11(1), 23. https://doi.org/10.1186/s13034-017-0160-9.

Aldao, A., Nolen-Hoeksema, S., \& Schweizer, S. (2010). Emotionregulation strategies across psychopathology: A meta-analytic review. Clinical Psychology Review, 30(2), 217-237. https://doi. org/10.1016/j.cpr.2009.11.004.

American Psychiatric Association. (2013). Diagnostic and statistical Manual of mental disorders (DSM-5) (5. Aufl.). American Psychiatric Association.
Coughlin, S. S. (1990). Recall bias in epidemiologic studies. Journal of Clinical Epidemiology, 43(1), 87-91. https://doi.org/10.1016/ 0895-4356(90)90060-3.

Darvesh, N., Radhakrishnan, A., Lachance, C. C., Nincic, V., Sharpe, J. P., Ghassemi, M., et al. (2020). Exploring the prevalence of gaming disorder and Internet gaming disorder: A rapid scoping review. Systematic Reviews, 9(1), 68. https://doi. org/10.1186/s13643-020-01329-2.

Döpfner, M., \& Petermann, F. (2012). Diagnostik psychischer Störungen im Kindes- und Jugendalter [Diagnosis of mental disorders in children and adolescents]. Hogrefe Verlag.

Estévez, A., Jáuregui, P., Sánchez-Marcos, I., López-González, H., \& Griffiths, M. D. (2017). Attachment and emotion regulation in substance addictions and behavioral addictions. Journal of Behavioral Addictions, 6(4), 534-544. https://doi.org/10.1556/ 2006.6.2017.086.

GWI. (2020). Coronavirus research: Multi-market research wave 4 | WARC. http://origin.warc.com/content/paywall/article/WarcResearch/GWI_Coronavirus_Research_Multimarket_research_ wave_4/132717 (accessed 25 June 2020).

Hawi, N. S., Samaha, M., \& Griffiths, M. D. (2019). The digital addiction scale for children: Development and validation. Cyberpsychology, Behavior, and Social Networking, 22(12), 771778. https://doi.org/10.1089/cyber.2019.0132.

Hooper, D., Coughlan, J., \& Mullen, M. R. (2008). Structural equation modelling: Guidelines for determining model fit. Electronic Journal of Business Research Methods, 6, 53-60.

Jeong, H., Yim, H. W., Lee, S.-Y., Lee, H. K., Potenza, M. N., Kwon, J.-H., et al. (2018). Discordance between self-report and clinical diagnosis of Internet gaming disorder in adolescents. Scientific Reports, 8(1), 10084. https://doi.org/10.1038/s41598-01828478-8.

Jo, Y. S., Bhang, S. Y., Choi, J. S., Lee, H. K., Lee, S. Y., \& Kweon, Y.S. (2019). Clinical characteristics of diagnosis for internet gaming disorder: Comparison of DSM-5 IGD and ICD-11 GD diagnosis. Journal of Clinical Medicine, 8(7). https://doi.org/10. 3390/jcm8070945.

Kaufman, E. A., Xia, M., Fosco, G., Yaptangco, M., Skidmore, C. R., \& Crowell, S. E. (2016). The difficulties in emotion regulation scale short form (DERS-SF): Validation and replication in adolescent and adult samples. Journal of Psychopathology and Behavioral Assessment, 38(3), 443-455.

Kindt, S., Szász-Janocha, C., Rehbein, F., \& Lindenberg, K. (2019). School-related risk factors of internet use disorders. International Journal of Environmental Research and Public Health, 16(24), 4938. https://doi.org/10.3390/ijerph16244938.

King, D. L., Chamberlain, S. R., Carragher, N., Billieux, J., Stein, D., Mueller, K., ... Delfabbro, P. H. (2020). Screening and assessment tools for gaming disorder: A comprehensive systematic review. Clinical Psychology Review, 101831. https://doi.org/10. 1016/j.cpr.2020.101831.

Kökönyei, G., Kocsel, N., Király, O., Griffiths, M. D., Galambos, A., Magi, A., et al. (2019). The role of cognitive emotion regulation strategies in problem gaming among adolescents: A nationally representative survey study. Frontiers in Psychiatry, 10, 273. https://doi.org/10.3389/fpsyt.2019.00273.

Ko, C.-H., Lin, H.-C., Lin, P.-C., \& Yen, J.-Y. (2019). Validity, functional impairment and complications related to Internet 
gaming disorder in the DSM-5 and gaming disorder in the ICD-11. Australian and New Zealand Journal of Psychiatry, 54(7), 707-718. https://doi.org/10.1177/0004867419881499.

Konrad, K., Firk, C., \& Uhlhaas, P. J. (2013). Brain development during adolescence: Neuroscientific insights into this developmental period. Deutsches Ärzteblatt International, 110(25), 425. https://doi.org/10.3238/arztebl.2013.0425.

Lemmens, J. S., Valkenburg, P. M., \& Gentile, D. A. (2015). The internet gaming disorder scale. Psychological Assessment, 27(2), 567-582. https://doi.org/10.1037/pas0000062.

Paschke, K., Austermann, M. I., \& Thomasius, R. (2020). Assessing ICD-11 gaming disorder in adolescent gamers: Development and validation of the gaming disorder scale for adolescents (GADIS-A). Journal of Clinical Medicine, 9(4), 993. https://doi. org/10.3390/jcm9040993.

Pontes, H. M., Schivinski, B., Sindermann, C., Li, M., Becker, B., Zhou, M., et al. (2019). Measurement and conceptualization of gaming disorder according to the world health organization framework: The development of the gaming disorder test. International Journal of Mental Health and Addiction, 1-21. https://doi.org/10.1007/s11469-019-00088-z.

Reed, G. M., First, M. B., Kogan, C. S., Hyman, S. E., Gureje, O., Gaebel, W., ... Saxena, S. (2019). Innovations and changes in the ICD-11 classification of mental, behavioural and neurodevelopmental disorders. World Psychiatry, 18(1), 3-19. https:// doi.org/10.1002/wps.20611.

Schneider, L. A., King, D. L., \& Delfabbro, P. H. (2018). Maladaptive coping styles in adolescents with internet gaming disorder symptoms. International Journal of Mental Health and Addiction, 16(4), 905-916. https://doi.org/10.1007/s11469-0179756-9.

statista. (2020a). Most popular Apple App Store categories in June 2020, by share of available apps. https://www.statista.com/ statistics/270291/popular-categories-in-the-app-store/(accessed 20 June 2020).

statista. (2020b). Online games. https://www.statista.com/outlook/ 212/100/online-games/worldwide (accessed 20 June 2020).

statista. (2020c). Internet access in German households. https://de. statista.com/statistik/daten/studie/153257/umfrage/haushaltemit-internetzugang-in-deutschland-seit-2002/(accessed 20 June 2020).

Sugaya, N., Shirasaka, T., Takahashi, K., \& Kanda, H. (2019). Biopsychosocial factors of children and adolescents with internet gaming disorder: A systematic review. BioPsychoSocial Medicine, 13(1), 3. https://doi.org/10.1186/s13030-019-0144-5.

Vadlin, S., Åslund, C., Rehn, M., \& Nilsson, K. W. (2015). Psychometric evaluation of the adolescent and parent versions of the gaming addiction identification test (GAIT). Scandinavian Journal of Psychology, 56(6), 726-735. https://doi.org/10.1111/sjop.12250.

Wakefield, J. C. (2015). DSM-5 substance use disorder: How conceptual missteps weakened the foundations of the addictive disorders field. Acta Psychiatrica Scandinavica, 132(5), 327334. https://doi.org/10.1111/acps.12446.

Wartberg, L., Zieglmeier, M., \& Kammerl, R. (2019). Accordance of adolescent and parental ratings of internet gaming disorder and their associations with psychosocial aspects. Cyberpsychology, Behavior, and Social Networking, 22(4), 264-270. https://doi. org/10.1089/cyber.2018.0456.

World Health Organization. (2018). International classification of diseases for mortality and morbidity statistics (11th Revision). https://icd.who.int/browse11/l-m/en (accessed 20 June 2020).

Yuan, K., Qin, W., Yu, D., Bi, Y., Xing, L., Jin, C., et al. (2016). Core brain networks interactions and cognitive control in internet gaming disorder individuals in late adolescence/early adulthood. Brain Structure and Function, 221(3), 1427-1442. https:// doi.org/10.1007/s00429-014-0982-7. 